\title{
Polycan, a $\beta$-glucan from Aureobasidium pullulans SM-2001, mitigates ovariectomy-induced osteoporosis in rats
}

\author{
MI YOUNG JUNG ${ }^{1 *}$, JOO WAN KIM ${ }^{2 *}$, KI YOUNG KIM $^{2}$, SEONG HUN CHOI ${ }^{1}$ and SAE KWANG KU ${ }^{1}$ \\ ${ }^{1}$ Department of Anatomy and Histology, College of Oriental Medicine, Daegu Haany University, Gyeongsan-si, \\ Gyeongsangbuk-do 712-715; ${ }^{2}$ Glucan Corp. Research Institute, Marine Bio-Industry Development Center, \\ Busan 619-912, Republic of Korea
}

Received October 31, 2014; Accepted November 5, 2015

DOI: $10.3892 / \mathrm{etm} .2016 .3485$

\begin{abstract}
The present study aimed to investigate the protective effects of Polycan, a $\beta$-glucan from Aureobasidium pullulans SM-2001, in a rat model of ovariectomy-induced osteoporosis. Ovariectomized (OVX) rats were orally administered 31.25, 62.5 or $125 \mathrm{mg} / \mathrm{kg} /$ day Polycan for 126 days, and alterations in body weight, bone mineral content, bone mineral density, failure load, histological profiles and histomorphometric indices were analyzed. In particular, serum levels of osteocalcin, bone-specific alkaline phosphatase (bALP), calcium and phosphorus, and the urine deoxypyridinoline/creatinine ratio, were measured. Furthermore, the femur, tibia and lumbar vertebrae were harvested from all rats, and histomorphometrical analyses were conducted in order to assess the mass and structure of the bones, and the rates of bone resorption and formation. One group of rats was treated with alendronate, which served as the reference drug. The results of the present study suggested that Polycan treatment was able to inhibit ovariectomy-induced alterations in bone resorption and turnover in a dose-dependent manner. In addition, the serum expression levels of bALP and all histomorphometrical indices for bone formation were markedly increased in the Polycan-treated groups. These results indicated that Polycan was able to preserve bone mass and strength, and increase the rate of bone formation in OVX rats; thus suggesting that Polycan may be considered a potential effective anti-osteoporosis agent.
\end{abstract}

Correspondence to: Professor Sae Kwang $\mathrm{Ku}$, Department of Anatomy and Histology, College of Oriental Medicine, Daegu Haany University, 290 Yugok-Dong, Gyeongsan-si, Gyeongsangbuk-do 712-715, Republic of Korea

E-mail: gucci200@hanmail.net

*Contributed equally

Key words: Aureobasidium pullulans, $\beta$-glucan, osteoporosis, ovariectomy, Polycan, rat

\section{Introduction}

Osteoporosis is a metabolic bone disease, which results from a disturbance in normal bone remodeling such that the balance shifts from bone formation to resorption; this in turn may lead to bone loss and the occurrence of fractures following mineral flux (1). Patients with osteoporosis exhibit a high frequency of fractures, and hip fractures in senile patients are particularly serious since they often limit the life of a patient (2). At present, osteoporosis affects $\sim 25$ million Americans (3). It has been estimated that a 50-year-old woman in the United States has an 11-18\% lifetime risk of suffering a hip fracture (3).

Numerous attempts have been made to develop novel agents for the prevention and treatment of bone diseases (4). At present, anti-resorptive agents, including biophosphonate, estrogen and calcitonin, are widely used (5); however, there is a requirement for highly effective resorptive inhibitors with improved safety and efficacy profiles. Anabolic agents, which are able to stimulate bone formation, are less well-known (6); however, trials to develop anabolic agents have been conducted, and have improved current understanding of the mechanisms underlying osteoblast differentiation and bone formation (7).

The estrogen-deficient, ovariectomized (OVX) rat model of osteoporosis has been considered useful for the evaluation of osteoporotic drugs, since various parameters associated with osteoporosis have been shown to be markedly decreased within 4-6 weeks following an ovariectomy (8). The OVX rat model of osteoporosis was selected for the present study as it approximates postmenopausal bone loss, as demonstrated by previous studies (8-10). A rat model was selected in particular as a 4-month study of rats is considered to be comparable to a 1-year study of humans (11). The effects of a drug in the OVX rat model may be assessed by detecting histomorphometrical alterations in bone mass, formation and resorption, and changes in bone weight, blood chemistry, urinalysis, bone mineral content (BMC), bone mineral density (BMD) and failure load (FL) (12).

Bone remodeling by bone cells is crucial in determining and increasing the bone mass during pathological conditions, including bone disorders (13). There are two major therapeutic strategies for patients with osteoporosis: Reducing bone turnover or increasing mineral deposition at bones. Alendronate and other bisphosphonates, which inhibit bone-turnover, have 
been prescribed to millions of patients worldwide, and have exhibited good safety profiles, with reports of only minor side effects $(14,15)$. Alendronate is a nitrogen-containing bisphosphonate and a potent inhibitor of bone resorption, which has been used to treat and prevent osteoporosis, in addition to exhibiting anti-osteoporosis effects in OVX animals and postmenopausal women $(16,17)$. Conversely, the parathyroid hormone, which has been developed to treat osteoporosis, is able to stimulate osteoblastic bone formation, increase bone mass and prevent vertebral fractures (18). Similarly, bone formation may be induced by treatment with strontium ranelate (19). Our previous mouse and in vitro studies demonstrated that Polycan was able to prevent bone loss by reducing net bone resorption and bone turnover $(20,21)$. In addition, an increase in bone-specific alkaline phosphatase (bALP) expression levels was indicative of an increase in bone formation following treatment with Polycan $(20,21)$.

$\beta$-glucan is a fiber-type complex polysaccharide derived from the cell wall of baker's yeast, oat and barley fiber, and numerous medicinal mushrooms (22). $\beta$-glucan is primarily used to enhance the immune system (23) and lower blood cholesterol levels (24). Polycan, which is purified $\beta$-glucan derived from Aureobasidium pullulans SM-2001, predominantly consists of $\beta-1,3 / 1,6$-glucan, as well as other organic materials, including amino acids, mono- or di-unsaturated fatty acids (linoleic and linolenic acids) and fibrous polysaccharide (25). Previous studies have demonstrated that Polycan was able to exert anti-osteoporosis effects, including inhibiting bone loss and accelerating bone formation in vitro and in OVX mice $(20,21)$, and promoting the healing of fractures (26). However, to the best of our knowledge, the effects of Polycan in a rat model of osteoporosis have yet to be evaluated. Therefore, the present study aimed to investigate the effects of Polycan (31.25, 62.5 and $125 \mathrm{mg} / \mathrm{kg}$ ), in comparison with the effects of alendronate, in a rat model of ovariectomy-induced osteoporosis.

\section{Materials and methods}

Rats. A total of 96 virgin Sprague-Dawley pathogen-free female rats (age, 6 weeks; weight, 137-173 g; Charles River Laboratories, Inc., Yokohama, Japan) were used in the present study, following a 7-day acclimatization period. The rats were maintained in polycarbonate cages at $20-25^{\circ} \mathrm{C}$ and $30-35 \%$ humidity, under a 12-h light/dark cycle and with access to food (Samyang Foods Co., Ltd., Wonju, Korea) and water ad libitum. A total of 80 rats were assigned to the experimental group (OVX-induced osteoporosis) and 16 rats were assigned to the sham control group. Following the ovariectomy procedure, 48 rats were selected for inclusion in the study, based on their body weight and behavior, according to the Guide for the Care and Use of Laboratory Animals from the Institute for Laboratory Animal Research (Washington, D.C., USA). The present study was approved by the Institute of Laboratory Animal Resources at Daegu Haany University (DHU2011-015; Gyeongsan, Korea).

Test articles, grouping and dosing. Polycan derived from A. pullulans SM-2001 (Glucan Co., Ltd., Busan, Korea) was stored in a refrigerator at $4^{\circ} \mathrm{C}$. The Polycan consisted of $13 \% \beta-1,3 / 1,6$-glucan and $40 \% \beta$-glucan, as demonstrated using analytical methods described in a previous study (25). The 48 rats were grouped as follows ( $n=8$ rats/group): A sham control group, an OVX control group, an alendronate group, and 3 groups of rats treated with $31.25,62.5$ and $125 \mathrm{mg} / \mathrm{kg}$ polycan, respectively. The Polycan was diluted in distilled water to $62.5,31.25$ and $125 \mathrm{mg} / \mathrm{kg}$, and was administered by gastric gavage using a 3-ml syringe. The Polycan was administered daily for 126 days, commencing one week following the ovariectomy procedure. A $10-\mathrm{mg} / \mathrm{kg}$ dose of alendronate (Merck \& Co., Inc., Whitehouse Station, NJ, USA) was generated by dissolving the alendronate in distilled water.

Surgical procedure. The rats in the experimental group underwent a bilateral ovariectomy following intraperitoneal injection with $25 \mathrm{mg} / \mathrm{kg}$ Zoletile (Virbac S.A., Carros, France), as described in a previous study (27). In the sham control group, the bilateral ovariectomy procedure was conducted without removal of the ovaries. Following the surgical procedure, the rats were divided into 6 groups (8 rats/group; a sham control group, an OVX control group, an alendronate group, and 3 polycan groups with various dosages).

Bone labeling. For dynamic histomorphometry, all rats were treated subcutaneously with $30 \mathrm{mg} / \mathrm{kg} / \mathrm{ml}$ tetracycline (Sigma-Aldrich, St. Louis, MO, USA) 13 days prior to sacrifice, and $8 \mathrm{mg} / \mathrm{kg} / \mathrm{ml}$ calcein (Sigma-Aldrich) 3 days prior to sacrifice. Briefly, tetracycline binds to newly formed bone at the bone/osteoid (unmineralized bone) interface where it exhibits linear fluorescence. Fluorescence was observed under a UV light microscope (model Eclipse 80i; Nikon Corporation, Tokyo, Japan). Animal sacrifice was carried out under anesthesia with $0.05 \mathrm{ml} / \mathrm{kg}$ Zoletile by exsanguination from the caudal vena cava. Animals with unintended problems (including cachexia and abnormal clinical signs) were sacrificed by cervical dislocation.

Body weight alterations. The body weight of all rats was measured prior to the initial treatment and once per week during the experimental period, concluding at sacrifice as described above. Blood was collected from the caudal vena cava and centrifuged at $720 \mathrm{x}$ g for $30 \mathrm{~min}$. The supernatant was collected using a micropipette. Prior to the body weight measurements at the initial dosing and at sacrifice, the experimental animals were fasted overnight in order to reduce the occurrence of errors due to feeding. Alterations in the body weight were calculated as the body weight at sacrifice minus the body weight at the initial treatment, in order to eliminate individual differences.

Serum biochemistry. Blood samples $(10 \mathrm{ml})$ were collected from the vena cava at sacrifice, and the serum was separated. All serum samples were frozen at $-40^{\circ} \mathrm{C}$ until required for further experimentation. Serum levels of osteocalcin $(\mathrm{ng} / \mathrm{ml})$ were detected using an Osteocalcina Myria kit (Technogenetics Srl, Milan, Italy) and a Packard Cobra II $\gamma$-counter (GMI, Inc., Ramsey, MN, USA). Serum levels of bALP(U/L) were detected using the commercially available Enzyme-Immunoassay kit (Metra $^{\text {TM }}$ bALP kit; cat. no. 8012; Quidel Corporation, San Diego, CA, USA). The serum calcium (Ca) levels ( $\mathrm{mg} / \mathrm{ml}$ ) were detected using the Orthocresolphthalein Complexone (OCPC) 
Table I. Rat body weight in the various groups.

\begin{tabular}{lllll}
\hline & \multicolumn{3}{c}{ Body weight } \\
\cline { 2 - 4 } Group & Day 0 (A) & Day 7 & Day 126 (B) & Gain (B - A) \\
\hline Sham control & $181.63 \pm 5.48$ & $207.75 \pm 3.92$ & $283.13 \pm 13.05$ & $101.50 \pm 12.81$ \\
OVX control & $182.25 \pm 4.89$ & $227.63 \pm 6.82^{\mathrm{a}}$ & $337.88 \pm 25.95^{\mathrm{a}}$ & $155.63 \pm 22.03^{\mathrm{a}}$ \\
Alendronate & $178.75 \pm 10.59$ & $225.25 \pm 16.15^{\mathrm{b}}$ & $318.38 \pm 37.75$ & $139.63 \pm 31.37^{\mathrm{a}}$ \\
Polycan & & & & \\
$31.25 \mathrm{mg} / \mathrm{kg}$ & $176.75 \pm 11.42$ & $223.10 \pm 18.02^{\mathrm{b}}$ & $329.88 \pm 41.27^{\mathrm{b}}$ & $153.13 \pm 33.36^{\mathrm{a}}$ \\
$62.5 \mathrm{mg} / \mathrm{kg}$ & $178.25 \pm 4.65$ & $227.88 \pm 8.63^{\mathrm{a}}$ & $338.25 \pm 22.93^{\mathrm{a}}$ & $160.00 \pm 21.73^{\mathrm{a}}$ \\
$125 \mathrm{mg} / \mathrm{kg}$ & $177.75 \pm 6.45$ & $221.63 \pm 9.46^{\mathrm{a}}$ & $333.00 \pm 32.26^{\mathrm{a}}$ & $125.25 \pm 30.41$ \\
\hline
\end{tabular}

Data are presented as the mean \pm standard deviation of 8 rats. All rats were fasted overnight prior to the first treatment and 126 days following the initial treatment. ${ }^{\mathrm{a}} \mathrm{P}<0.01$ and ${ }^{\mathrm{b}} \mathrm{P}<0.05$ vs. sham control group. OVX, ovariectomized.

method and an automated blood analyzer (TBA 200FR; Toshiba, Tokyo, Japan). Briefly, the OCPC complexone (P5631; Sigma-Aldrich) method is based on the reaction of $\mathrm{Ca}^{2+}$ with o-cresolphthalein complexone in an alkaline solution, which forms an intense violet fluorescence which maximally absorbs at $577 \mathrm{~nm}$. 8-hydroxyquionline is added to prevent interference by magnesium and iron. The serum phosphorus $(\mathrm{P})$ levels were detected using the kinetic ultraviolet (UV) method using a blood biochemistry autoanalyzer (Dri-Chem NX500i; Fujifilm Medical System Co., Ltd., Tokyo, Japan).

Urinalysis. Urine from individual rats was collected over a 24-h period following the final treatment, and was centrifuged at $720 \mathrm{x} \mathrm{g}$ for $10 \mathrm{~min}$ to remove sediments. The levels of deoxypyridinoline (Dpd; $\mathrm{nM}$ ) in the urine were detected using a commercial Enzyme-Immunoassay kit (Metra ${ }^{\mathrm{TM}}$ Dpd kit; cat. no. 8007; Quidel Corporation) and an enzyme-linked immunosorbent assay plate reader (Tecan Schweiz AG, Männedorf, Switzerland). The levels of creatinine (g/day) in the urine were detected using the Jaffe reaction and an automated urine analyzer (model TBA-2000FR; Toshiba). In addition, the Dpd/creatinine ratios were measured.

$B M C$. Following sacrifice, the right side of the femur and tibia, as well as the $4^{\text {th }}$ lumbar vertebrae $\left(\mathrm{L}_{4}\right)$, were harvested and dried at $120^{\circ} \mathrm{C}$ for $8 \mathrm{~h}$. The dried tibiae underwent carbonization at $800^{\circ} \mathrm{C}$ for $6 \mathrm{~h}$ in a furnace, after which they were dissolved in nitric acid. In a dissolved solution, the $\mathrm{Ca}$ and $\mathrm{P}$ concentrations $(\mathrm{mg} / \mathrm{g})$ were calculated using the OCPC and kinetic UV methods, respectively. In addition, the $\mathrm{Ca} / \mathrm{P}$ ratio was calculated using the following formula: $\mathrm{Ca} / \mathrm{P}$ ratio $=($ bone Ca content/bone $\mathrm{P}$ content) x 100.

$B M D$ and $F L$. The BMD $\left(\mathrm{g} / \mathrm{cm}^{2}\right)$ of the epiphyseal plates and body of the right femur and tibia was measured using dual-energy X-ray absorption (Lunar PIXImus; GE Healthcare Bio-Sciences, Pittsburgh, PA, USA). In addition, the BMD of the articulate regions and body of the $\mathrm{L}_{4}$ was determined prior to BMC measurement. The bone strength was measured in terms of FL. The FL (newtons, $N$ ) of the mid-shaft regions of the right femur and tibia was measured using a three-point bending test to failure on a computerized testing machine (Instron 6022; Instron, Norwood, MA, USA; speed, $20 \mathrm{~mm} / \mathrm{min}$ ). In addition, the FL of the $\mathrm{L}_{4}$ body was measured.

Histology and histomorphometry. The left side of the femur and tibia, and the $5^{\text {th }}$ lumbar vertebrae $\left(\mathrm{L}_{5}\right)$ of each rat were separated, dehydrated in a graded series of ethanol and xylene, and embedded undecalcified in modified methyl methacrylate (Araldite/Embed Embedding kit; cat. no. 13940; Electron Microscopy Sciences, Hatfield, PA, USA). Subsequently, the samples were sectioned (3-4 $\mu \mathrm{m})$ and stained with hematoxylin and eosin staining. A section was left unstained for dynamic histomorphometry. For each prepared sample, the histological profiles (osteoporotic hole) were observed under a microscope (Carl Zeiss AG, Oberkochen, Germany).

Bone histomorphometry was conducted using automated image analysis processing software (analySIS ${ }^{\circledR}$ AUTO; SiS Sensoren Instrumente Systeme GmbH, Schwentinental, Germany), as outlined in a previous report (28). Briefly, in order to determine the bone mass and structure, the trabecular bone volume (Tb.Ar), thickness (Tb.Wi), number (N.Tb) and length (Tb.Pm), and the cortical bone thickness (Ct.Wi), were measured. In order to determine the extent of bone resorption, the osteoclast cell number (N.Oc) in uniform regions of the epiphyseal plates (N/epiphyseal), and the osteoclast cell surface/bone surface (Oc/BS\%), were determined. In order to measure the rate of bone formation ( $\mu \mathrm{m} / \mathrm{day})$, the mineral appositional rate (MAR) in the trabecular and cortical regions was determined by dividing the distance between the midpoints of the two labels by the time interval between the labeling periods (10 days). The single labeled surface (sL.Pm) corresponded to the trabecular or cortical surface covered with single label (tetracycline only), and was expressed as a percentage of the bone surface. The double labeled surface $(\mathrm{dL}$. $\mathrm{Pm}$ ) corresponded to the bone surface covered with both labels (tetracycline and calcein) and was expressed as a percentage of the bone surface. The mineralizing surface (Md.Pm) was calculated using the following equation: $\operatorname{Md} . \operatorname{Pm}(\%)=[(1 / 2$ sL.PM) + dL.Pm]. The surface referent bone formation rate 
Table II. Alterations in serum biochemistry.

\begin{tabular}{lcccc}
\hline Group & Osteocalcin $(\mathrm{ng} / \mathrm{ml})$ & bALP $(\mathrm{U} / \mathrm{l})$ & $\mathrm{Ca}(\mathrm{mg} / \mathrm{dl})$ & $\mathrm{P}(\mathrm{mg} / \mathrm{dl})$ \\
\hline Sham control & $1.349 \pm 0.185$ & $1.425 \pm 0.238$ & $9.338 \pm 0.774$ & $6.650 \pm 0.960$ \\
OVX control & $2.031 \pm 0.205^{\mathrm{a}}$ & $0.963 \pm 0.160^{\mathrm{a}}$ & $8.400 \pm 0.288^{\mathrm{a}}$ & $5.570 \pm 0.289^{\mathrm{a}}$ \\
Alendronate & $1.621 \pm 0.276^{\mathrm{b}}$ & $1.000 \pm 0.273^{\mathrm{a}}$ & $8.738 \pm 0.667$ & $5.286 \pm 0.576^{\mathrm{a}}$ \\
Polycan & & & & \\
$31.25 \mathrm{mg} / \mathrm{kg}$ & $1.908 \pm 0.086^{\mathrm{a}}$ & $1.213 \pm 0.181^{\mathrm{c}}$ & $8.863 \pm 0.555^{\mathrm{c}}$ & $5.595 \pm 0.452^{\mathrm{a}}$ \\
$62.5 \mathrm{mg} / \mathrm{kg}$ & $1.801 \pm 0.141^{\mathrm{a}, \mathrm{c}}$ & $1.238 \pm 0.220^{\mathrm{b}}$ & $8.963 \pm 0.504^{\mathrm{c}}$ & $6.028 \pm 0.339^{\mathrm{c}}$ \\
$125 \mathrm{mg} / \mathrm{kg}$ & $1.760 \pm 0.167^{\mathrm{a}, \mathrm{b}}$ & $1.300 \pm 0.141^{\mathrm{b}}$ & $9.013 \pm 0.344^{\mathrm{b}}$ & $6.044 \pm 0.417$ \\
\hline
\end{tabular}

Data are presented as the mean \pm standard deviation of 8 rats. ${ }^{\mathrm{a}} \mathrm{P}<0.01$ vs. sham control group. ${ }^{\mathrm{b}} \mathrm{P}<0.01$ and ${ }^{\mathrm{c}} \mathrm{P}<0.05$ vs. OVX control group. OVX, ovariectomized; bALP, bone-specific alkaline phosphatase; Ca, calcium; P, phosphorus.

Table III. Alterations in urinalysis.

\begin{tabular}{|c|c|c|c|}
\hline Group & Dpd (nM) & Creatinine (g/day) & Dpd/creatinine (nM/g/day) \\
\hline Sham control & $37.13 \pm 6.36$ & $0.0061 \pm 0.0016$ & $6,589.14 \pm 2,065.59$ \\
\hline OVX control & $57.53 \pm 4.99^{\mathrm{a}}$ & $0.0059 \pm 0.0009$ & $9,948.74 \pm 1,681.29^{\mathrm{a}}$ \\
\hline Alendronate & $35.94 \pm 12.75^{b}$ & $0.0057 \pm 0.0013$ & $6,344.94 \pm 1,898.94^{c}$ \\
\hline \multicolumn{4}{|l|}{ Polycan } \\
\hline $31.25 \mathrm{mg} / \mathrm{kg}$ & $49.73 \pm 10.15^{\mathrm{d}}$ & $0.0068 \pm 0.0019$ & $7,858.53 \pm 2,496.99$ \\
\hline $62.5 \mathrm{mg} / \mathrm{kg}$ & $49.73 \pm 5.33^{\mathrm{a}, \mathrm{c}}$ & $0.0065 \pm 0.0006$ & $7,781.32 \pm 1,156.59^{\mathrm{b}}$ \\
\hline $125 \mathrm{mg} / \mathrm{kg}$ & $49.69 \pm 8.70^{\mathrm{a}, \mathrm{b}}$ & $0.0065 \pm 0.0006$ & $7,751.24 \pm 1,556.92^{\mathrm{b}}$ \\
\hline
\end{tabular}

Data are presented as the mean \pm standard deviation of 8 rats. ${ }^{\mathrm{a}} \mathrm{P}<0.01$ and ${ }^{\mathrm{d}} \mathrm{P}<0.05$ vs. sham control group. ${ }^{\mathrm{b}} \mathrm{P}<0.05$ and ${ }^{\mathrm{c}} \mathrm{P}<0.01$ vs. $\mathrm{OVX}$ control group. OVX, ovariectomized; Dpd, deoxypyridinoline.

(BFR/BS), which corresponded to the amount of new bone mineralized at the tissue level per $\mathrm{mm}^{2}$ of bone surface area per day, was calculated using the following equation: BFR/BS $\left(\mu \mathrm{m}^{3} / \mu \mathrm{m}^{2} /\right.$ day $)=$ Md.Pm $\times$ MAR.

Statistical analysis. Data are presented as the mean \pm standard deviation. Data was analyzed using one-way analysis of variance, followed by a least-significant difference multiple comparison test, in order to determine which pairs of group comparisons were significantly different. When a significant difference was detected using the Kruskal-Wallis $\mathrm{H}$ test, a Mann-Whitney U test was conducted, in order to determine the specific pairs of group comparisons that were significantly different. Statistical analyses were performed using SPSS software version 14.0 (SPSS, Inc., Chicago, IL, USA). $\mathrm{P}<0.05$ and $\mathrm{P}<0.01$ were considered to indicate statistically significant and highly statistically significant differences, respectively.

\section{Results}

Alterations in body weight. A significant increase in body weight was detected in the OVX rats compared with the sham control group at 7 and 126 days following the initial treatment $(\mathrm{P}<0.01)$. There was no significant difference in body weight alterations between the treated groups (alendronate and Polycan-treated groups) and the OVX control group (Table I).

Alterations in serum biochemistry. The serum levels of osteocalcin were significantly increased in the OVX control group compared with the sham control group $(\mathrm{P}<0.01$; Table II). A significant reduction in the serum levels of bALP, $\mathrm{Ca}$ and $\mathrm{P}$ was detected in the OVX control group compared with the sham control group $(\mathrm{P}<0.01)$. Conversely, marked dose-dependent reductions in the serum levels of osteocalcin, and elevations in the serum levels of bALP, Ca and P were detected in the Polycan-treated groups compared with the OVX control group $(\mathrm{P}<0.05)$. The serum levels of osteocalcin were significantly decreased in the alendronate-treated group compared with the OVX control group $(\mathrm{P}<0.01)$; however, no significant differences in the serum levels of bALP, Ca and $\mathrm{P}$ were detected between the alendronate-treated group and the OVX control group (Table II).

Alterations in urinalysis. Significantly increased urine Dpd levels and Dpd/creatinine ratios were detected in the OVX control group compared with the sham control group $(\mathrm{P}<0.01)$. Conversely, dose-dependent reductions in the urine Dpd levels and Dpd/creatinine ratios were detected in the Polycan-treated groups compared with the OVX control group (Table III). 
Table IV. Alterations in bone mineral contents.

\begin{tabular}{|c|c|c|c|c|c|c|}
\hline \multirow[b]{2}{*}{ Bone } & \multirow[b]{2}{*}{ Sham control } & \multirow[b]{2}{*}{ OVX control } & \multirow[b]{2}{*}{ Alendronate } & \multicolumn{3}{|c|}{ Polycan-treated groups } \\
\hline & & & & $31.25 \mathrm{mg} / \mathrm{kg}$ & $62.5 \mathrm{mg} / \mathrm{kg}$ & $125 \mathrm{mg} / \mathrm{kg}$ \\
\hline \multicolumn{7}{|l|}{ Femur } \\
\hline $\mathrm{Ca} \mathrm{mg} / \mathrm{g}$ bone & $170.86 \pm 13.75$ & $95.82 \pm 17.78^{a}$ & $120.95 \pm 12.40^{\mathrm{a}, \mathrm{b}}$ & $106.05 \pm 14.02^{c}$ & $125.12 \pm 9.03^{\mathrm{a}, \mathrm{b}}$ & $138.07 \pm 16.11^{\mathrm{a}, \mathrm{b}}$ \\
\hline $\mathrm{P} \mathrm{mg} / \mathrm{g}$ bone & $98.71 \pm 7.56$ & $57.29 \pm 11.04^{\mathrm{a}}$ & $73.60 \pm 13.18^{\mathrm{a}, \mathrm{b}}$ & $63.19 \pm 9.20^{c}$ & $76.48 \pm 11.47^{\mathrm{a}, \mathrm{d}}$ & $83.30 \pm 10.28^{\mathrm{c}, \mathrm{d}}$ \\
\hline $\mathrm{Ca} / \mathrm{P}$ ratio & $1.74 \pm 0.16$ & $1.70 \pm 0.34$ & $1.69 \pm 0.34$ & $1.70 \pm 0.28$ & $1.67 \pm 0.29$ & $1.68 \pm 0.29$ \\
\hline \multicolumn{7}{|l|}{ Tibia } \\
\hline $\mathrm{Ca} \mathrm{mg} / \mathrm{g}$ bone & $196.13 \pm 9.74$ & $103.82 \pm 15.02^{\mathrm{a}}$ & $133.37 \pm 21.61^{\mathrm{a}, \mathrm{d}}$ & $110.14 \pm 14.66^{c}$ & $128.77 \pm 10.45^{\mathrm{a}, \mathrm{d}}$ & $140.72 \pm 15.00^{\mathrm{a}, \mathrm{d}}$ \\
\hline P mg/g bone & $99.66 \pm 11.83$ & $52.67 \pm 7.66^{\mathrm{a}}$ & $67.93 \pm 7.47^{\mathrm{a}, \mathrm{d}}$ & $55.54 \pm 6.04^{\mathrm{c}}$ & $67.11 \pm 6.52^{\mathrm{a}, \mathrm{d}}$ & $70.00 \pm 7.12^{\mathrm{a}, \mathrm{d}}$ \\
\hline $\mathrm{Ca} / \mathrm{P}$ ratio & $1.99 \pm 0.22$ & $1.99 \pm 0.31$ & $1.99 \pm 0.42$ & $2.00 \pm 0.31$ & $1.93 \pm 0.17$ & $2.03 \pm 0.28$ \\
\hline \multicolumn{7}{|l|}{$\mathrm{L}_{4}$} \\
\hline $\mathrm{Ca} \mathrm{mg} / \mathrm{g}$ bone & $210.14 \pm 8.35^{\mathrm{a}}$ & $124.41 \pm 12.48^{\mathrm{a}}$ & $138.50 \pm 9.19^{\mathrm{a}}$ & $138.10 \pm 13.87^{\mathrm{c}}$ & $146.84 \pm 16.78^{a, b}$ & $155.79 \pm 11.09^{\mathrm{a}, \mathrm{d}}$ \\
\hline $\mathrm{P} \mathrm{mg} / \mathrm{g}$ bone & $113.50 \pm 13.77^{\mathrm{a}}$ & $66.91 \pm 8.53^{\mathrm{a}}$ & $74.12 \pm 7.24^{\mathrm{a}}$ & $75.61 \pm 12.46^{\mathrm{c}}$ & $78.77 \pm 10.05^{\mathrm{a}, \mathrm{b}}$ & $83.25 \pm 6.81^{\mathrm{a}, \mathrm{d}}$ \\
\hline $\mathrm{Ca} / \mathrm{P}$ ratio & $1.87 \pm 0.23$ & $1.90 \pm 0.45$ & $1.88 \pm 0.20$ & $1.87 \pm 0.38$ & $1.88 \pm 0.23$ & $1.88 \pm 0.16$ \\
\hline
\end{tabular}

Data are presented as the mean \pm standard deviation of 8 rats. ${ }^{\mathrm{a}} \mathrm{P}<0.01$ and ${ }^{\mathrm{c}} \mathrm{P}<0.05$ vs. sham control group. ${ }^{\mathrm{b}} \mathrm{P}<0.05$ and ${ }^{\mathrm{d}} \mathrm{P}<0.01$ vs. $\mathrm{OVX}$ control group. OVX, ovariectomized; $\mathrm{L}_{4}$, 4th lumbar vertebrae.

Table V. Alterations in BMD and FL in the rat femur, tibia and $\mathrm{L}_{4}$ verterae.

\begin{tabular}{lcccccc}
\hline & & & & \multicolumn{3}{c}{ Polycan-treated groups } \\
\cline { 6 - 7 } Bone & Sham control & OVX control & Alendronate & $31.25 \mathrm{mg} / \mathrm{kg}$ & $62.5 \mathrm{mg} / \mathrm{kg}$ & $125 \mathrm{mg} / \mathrm{kg}$ \\
\hline Femur & & & & & & \\
Epiphyseal BMD & $0.378 \pm 0.040$ & $0.213 \pm 0.032^{\mathrm{a}}$ & $0.513 \pm 0.107^{\mathrm{a}, \mathrm{b}}$ & $0.253 \pm 0.026^{\mathrm{a}, \mathrm{c}}$ & $0.286 \pm 0.030^{\mathrm{a}, \mathrm{b}}$ & $0.293 \pm 0.021^{\mathrm{a}, \mathrm{b}}$ \\
Mid-shaft BMD & $0.336 \pm 0.036$ & $0.189 \pm 0.025^{\mathrm{a}}$ & $0.224 \pm 0.027^{\mathrm{a}, \mathrm{c}}$ & $0.228 \pm 0.032^{\mathrm{a}, \mathrm{c}}$ & $0.251 \pm 0.037^{\mathrm{a}, \mathrm{b}}$ & $0.265 \pm 0.029^{\mathrm{a}, \mathrm{b}}$ \\
FL & $119.03 \pm 8.68$ & $70.48 \pm 11.39^{\mathrm{a}}$ & $83.50 \pm 7.70^{\mathrm{a}, \mathrm{c}}$ & $78.03 \pm 6.39^{\mathrm{a}}$ & $86.30 \pm 6.08^{\mathrm{b}, \mathrm{c}}$ & $88.33 \pm 10.02^{\mathrm{a}, \mathrm{c}}$ \\
Tibia & & & & & & \\
Epiphyseal BMD & $0.305 \pm 0.023$ & $0.199 \pm 0.017^{\mathrm{a}}$ & $0.385 \pm 0.066^{\mathrm{a}, \mathrm{b}}$ & $0.221 \pm 0.034^{\mathrm{a}}$ & $0.249 \pm 0.026^{\mathrm{a}, \mathrm{b}}$ & $0.268 \pm 0.046^{\mathrm{b}}$ \\
Mid-shaft BMD & $0.291 \pm 0.015$ & $0.179 \pm 0.023^{\mathrm{a}}$ & $0.195 \pm 0.024^{\mathrm{a}}$ & $0.209 \pm 0.020^{\mathrm{a}, \mathrm{c}}$ & $0.224 \pm 0.025^{\mathrm{a}, \mathrm{b}}$ & $0.243 \pm 0.042^{\mathrm{a}, \mathrm{b}}$ \\
FL & $79.61 \pm 2.44$ & $50.96 \pm 6.27^{\mathrm{a}}$ & $55.69 \pm 11.18^{\mathrm{a}}$ & $57.25 \pm 4.78^{\mathrm{a}}$ & $62.06 \pm 3.52^{\mathrm{a}, \mathrm{b}}$ & $63.41 \pm 5.05^{\mathrm{a}, \mathrm{b}}$ \\
L $_{4}$ & & & & & & \\
Epiphyseal BMD & $0.338 \pm 0.034$ & $0.225 \pm 0.023^{\mathrm{a}}$ & $0.255 \pm 0.030^{\mathrm{a}, \mathrm{c}}$ & $0.249 \pm 0.026^{\mathrm{a}}$ & $0.258 \pm 0.025^{\mathrm{a}, \mathrm{c}}$ & $0.293 \pm 0.015^{\mathrm{a}, \mathrm{b}}$ \\
Mid-shaft BMD & $0.305 \pm 0.021$ & $0.186 \pm 0.028^{\mathrm{a}}$ & $0.199 \pm 0.022^{\mathrm{a}}$ & $0.205 \pm 0.016^{\mathrm{a}}$ & $0.238 \pm 0.019^{\mathrm{a}, \mathrm{b}}$ & $0.256 \pm 0.033^{\mathrm{a}, \mathrm{b}}$ \\
FL & $66.20 \pm 5.35$ & $42.20 \pm 8.25^{\mathrm{a}}$ & $50.06 \pm 11.14^{\mathrm{a}}$ & $48.93 \pm 5.85^{\mathrm{a}}$ & $50.60 \pm 6.03^{\mathrm{a}, \mathrm{c}}$ & $57.08 \pm 6.25^{\mathrm{b}, \mathrm{d}}$ \\
\hline
\end{tabular}

Data are presented as the mean \pm standard deviation of 8 rats. ${ }^{\mathrm{a}} \mathrm{P}<0.01$ and ${ }^{\mathrm{d}} \mathrm{P}<0.05$ vs. sham control group. ${ }^{\mathrm{b}} \mathrm{P}<0.01$ and ${ }^{\mathrm{c}} \mathrm{P}<0.05$ vs. $\mathrm{OVX}$ control group. OVX, ovariectomized; $\mathrm{L}_{4}$, 4th lumbar vertebrae; BMD, bone mineral density; FL, failure load.

Alterations in BMC. Significantly decreased levels of $\mathrm{Ca}$ and $\mathrm{P}$ were detected in the femur, tibia and $\mathrm{L}_{4}$ of the $\mathrm{OVX}$ control group compared with the sham control group $(\mathrm{P}<0.01)$. Conversely, significant increases in the $\mathrm{BMC}$ were detected in all treated groups $(\mathrm{P}<0.05)$. No significant alterations in $\mathrm{Ca} / \mathrm{P}$ ratios were detected in any of the groups (Table IV).

Alterations in BMD and FL. The BMD and FL of the tibia, femur and $\mathrm{L}_{4}$ were significantly decreased in the OVX control group compared with the sham control group $(\mathrm{P}<0.01)$.
Conversely, significantly increased BMD and FL were detected in all three types of bone in the majority of the Polycan-treated groups compared with the OVX control group $(\mathrm{P}<0.05)$. However, the rats treated with $31.25 \mathrm{mg} / \mathrm{kg}$ Polycan did not exhibit significant increases in BMD and FL compared with the OVX control group (Table V).

Alterations in bone histomorphometry. Relatively well-developed and compact trabecular and cortical bone regions were observed in the femur of the sham control 


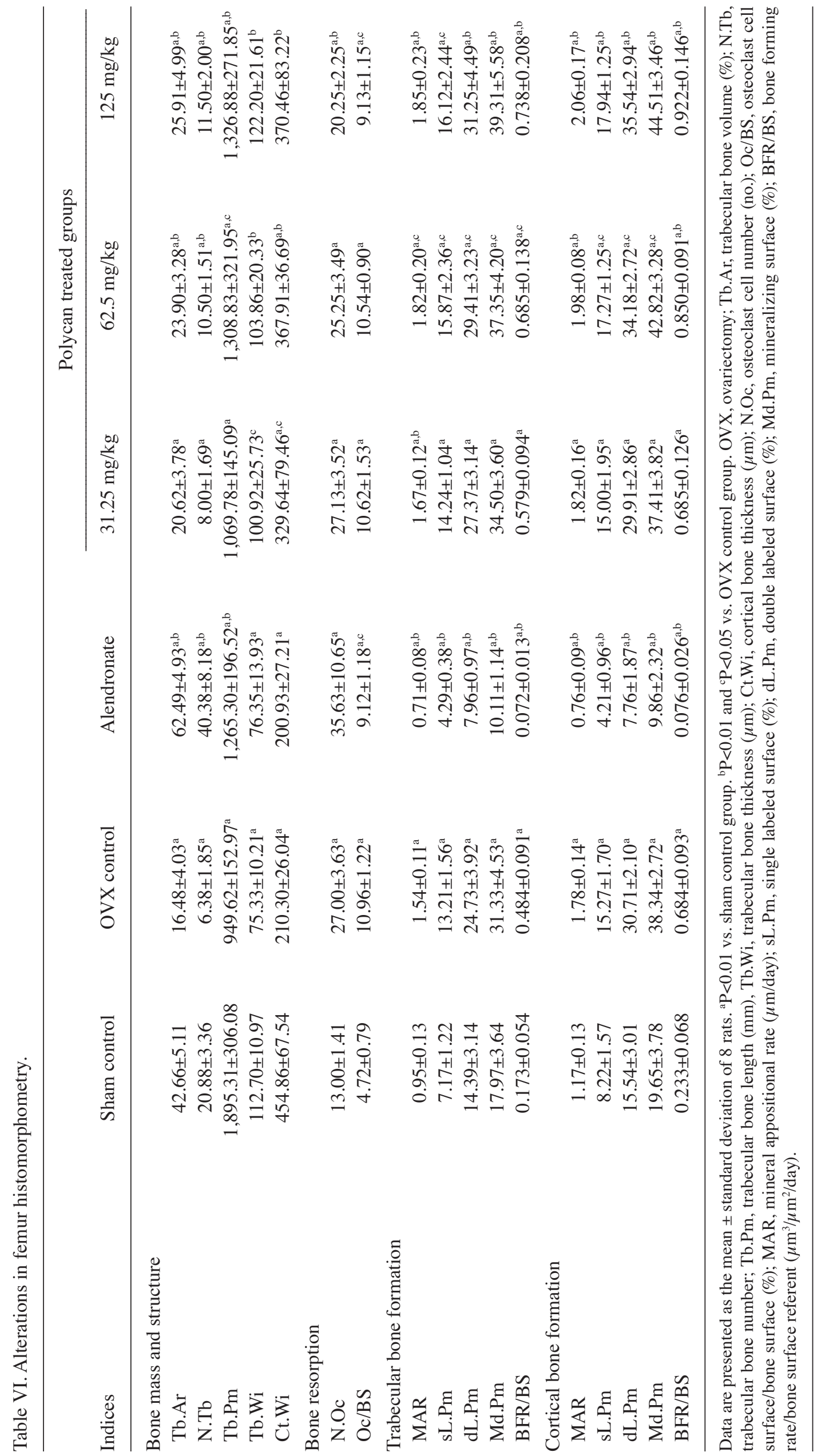




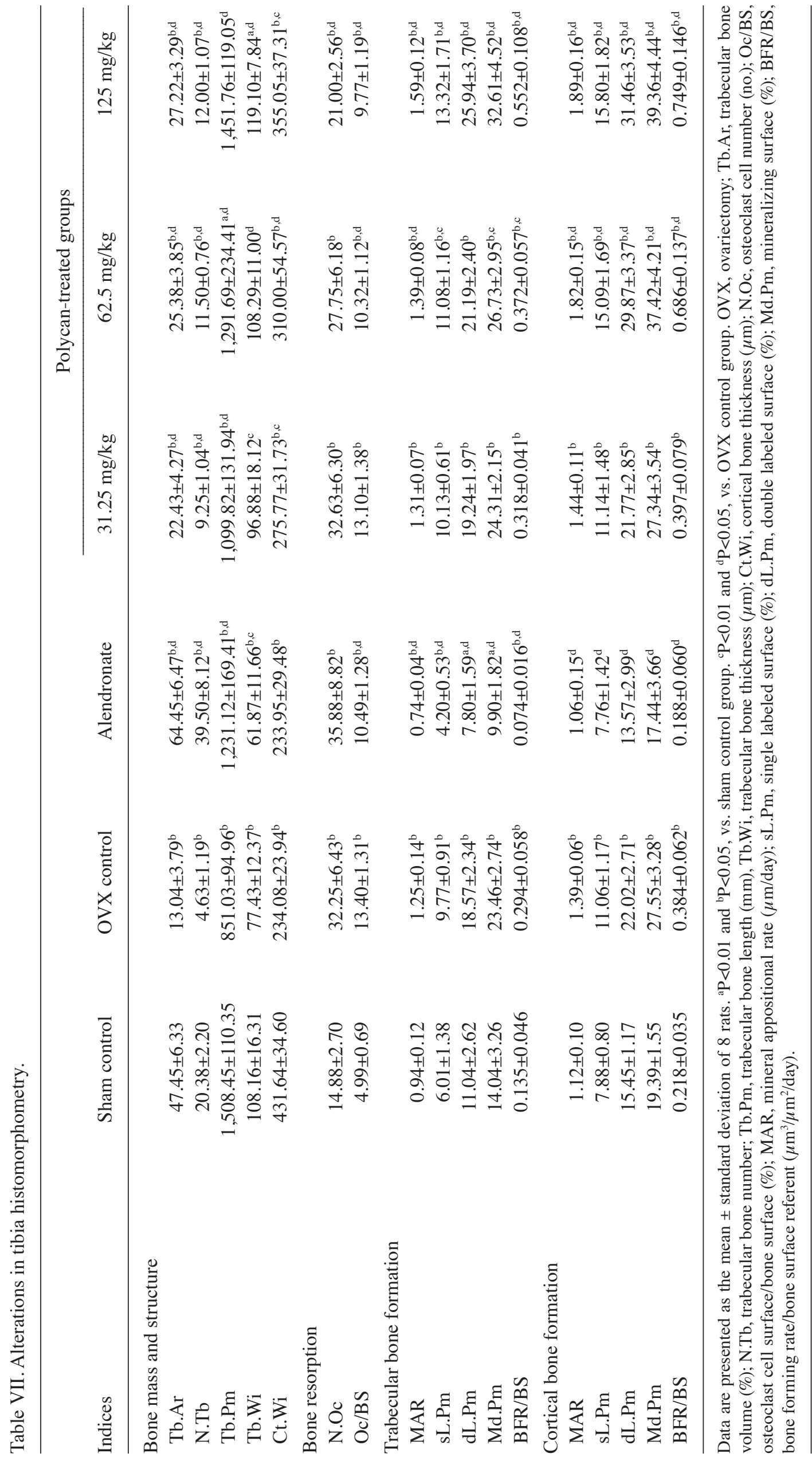




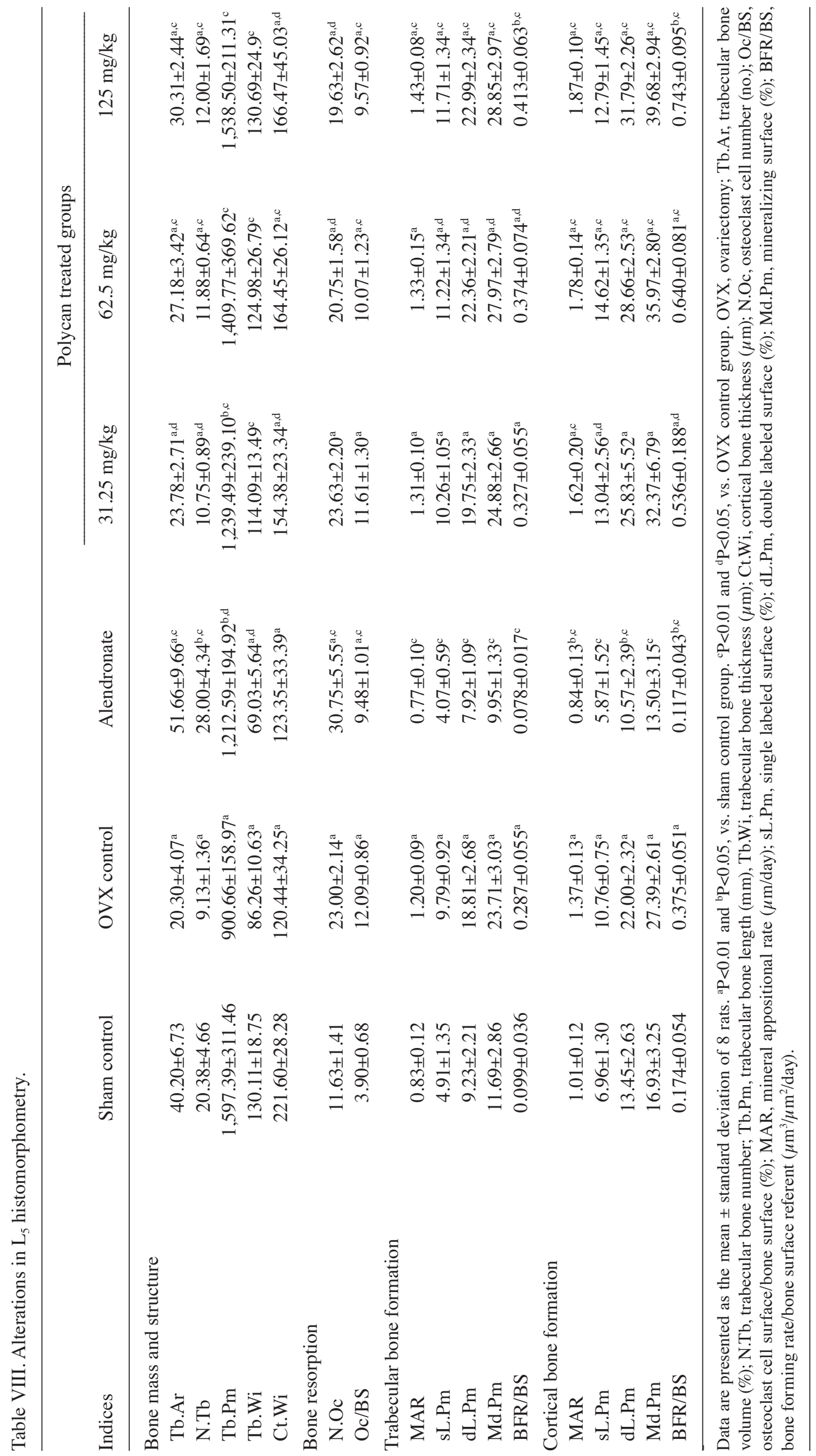



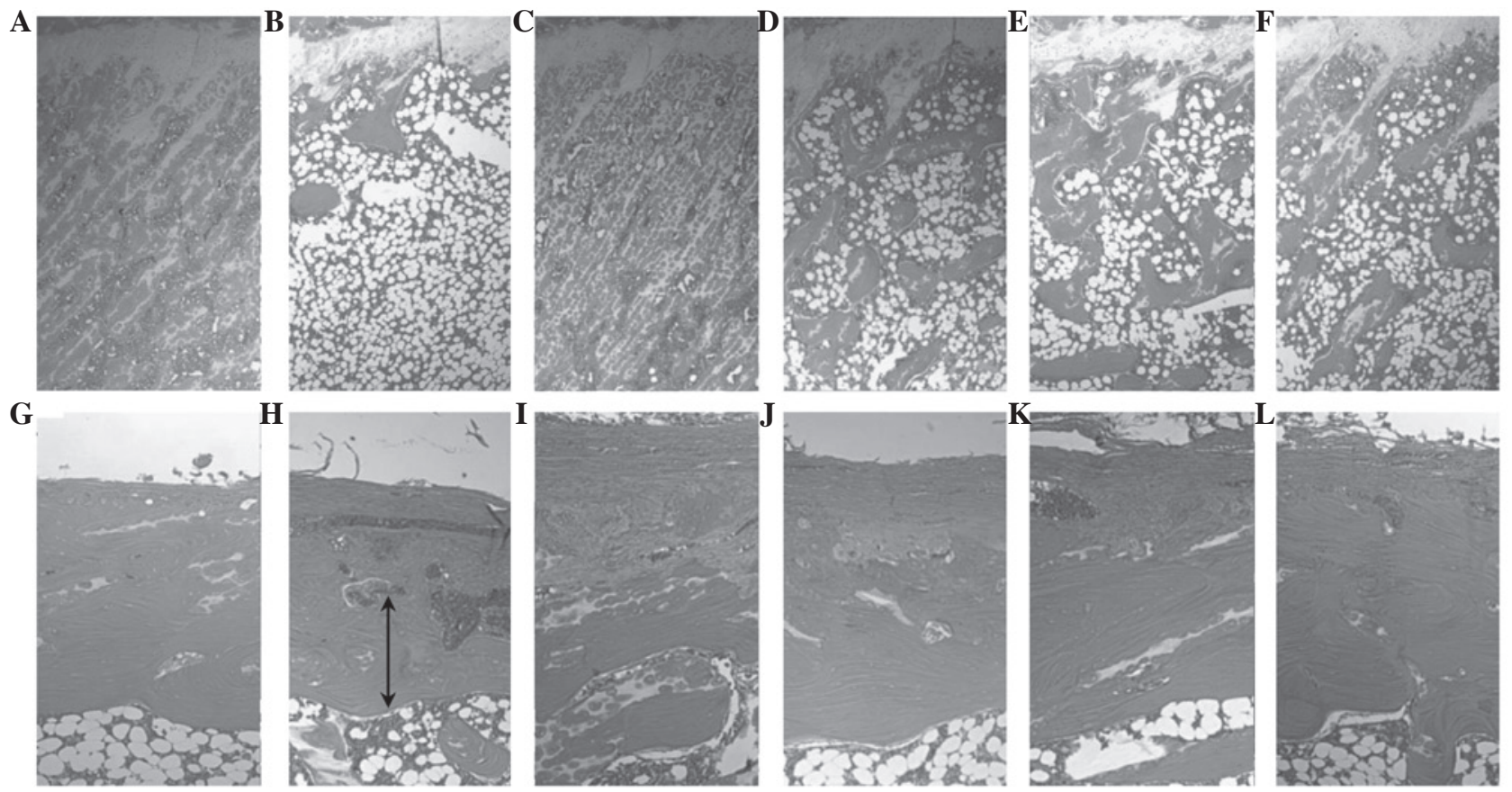

Figure 1. Histological profiles of the femur of the (A and B) sham, (C and D) ovariectomized control and (E and F) alendronate-treated groups, and the $(\mathrm{G}$ and $\mathrm{H}$ ) 31.25, (I and J) 62.5 and $(\mathrm{K}$ and $\mathrm{L}) 125 \mathrm{mg} / \mathrm{kg}$ Polycan-treated groups. Polycan inhibited the ovariectomy-induced reduction in trabecular bone mass and cortical bone thickness in a dose-dependent manner. Conversely, alendronate attenuated the ovariectomy-induced reduction in trabecular bone mass only. A, C, E, G, I and K display epiphyseal plate-trabecular bone regions (magnification, x25); B, D, F, H, J, and L display cortical bone regions (magnification, x50). Arrows represent the cortical thickness. All sections were stained with hematoxylin and eosin.
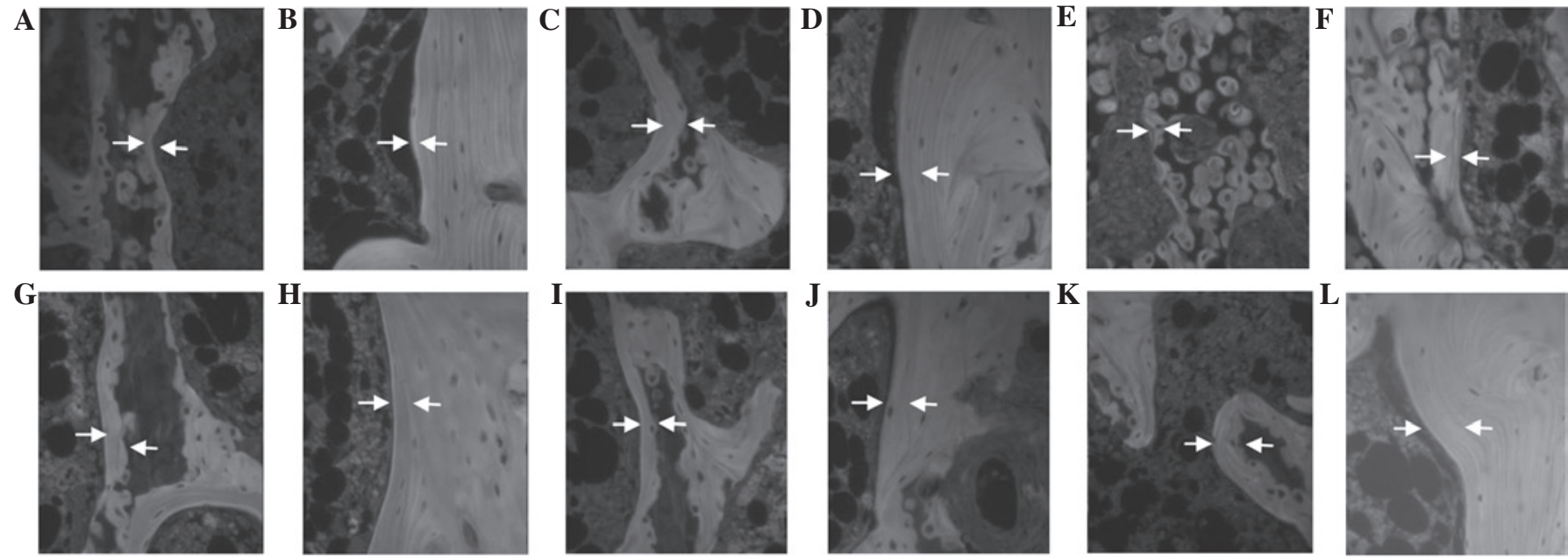

Figure 2. Fluorescent histological profiles of the femur of the (A and B) sham, (C and D) ovariectomized (OVX) control and (E and F) alendronate-treated groups, and the (G and H) 31.25, (I and J) 62.5 and $(\mathrm{K}$ and $\mathrm{L}) 125 \mathrm{mg} / \mathrm{kg}$ Polycan-treated groups. The mineral apposition rate (MAR) was markedly increased in the trabecular and cortical bone regions of the femur in the Polycan-treated rats, in a dose-dependent manner, as compared with the OVX control group. Conversely, the MAR was markedly decreased in both bone regions of the femur in the alendronate-treated rats, as compared with the OVX control group. A, C, E, G, I and K display trabecular bone regions (magnification, x200); B, D, F, H, J and L display cortical bone regions (magnification, x200). Arrows indicate the tetracycline and calcein labeled lines. The distant between the arrows represents the MAR over a 10-day period.

group rats. Conversely, the OVX control group exhibited a histological profile that was typical for osteoporosis, including marked reductions in the trabecular and cortical bone masses, and increased levels of connective tissue in the periosteum of the cortical bone due to the resorption of osteoid tissues. Alterations in the bone histomorphometry were markedly decreased in the Polycan-treated groups, particularly within the cortical bone, as compared with the OVX control group (Fig. 1). In the OVX control group, an increased MAR, as indicated by the distance between the tetracycline and calcein labeling regions, was observed in the cortical and trabecular bone regions, as compared with the sham control group. Conversely, a dose-dependent increase in MAR was detected in the cortical and trabecular bone regions of the Polycan-treated groups, as compared with the OVX control group. In the alendronate-treated group, the MAR in all three bones tested was markedly decreased compared with the OVX control group (Fig. 2). 
Bone mass and structures. Significant reductions in the Tb.Ar, N.Tb, Tb.Wi, Tb.Pm and Ct.Wi were detected in the tibia, femur and $\mathrm{L}_{5}$ of the OVX control rats, as compared with the sham control rats $(\mathrm{P}<0.01)$. Conversely, significant $(\mathrm{P}<0.05)$ dose-dependent increases in the histomorphometric indices for bone mass and structure were detected in all three bones from the Polycan-treated rats compared with the OVX control, with the exception of the $31.25 \mathrm{mg} / \mathrm{kg}$-treated group, in which no significant increases in these indices were observed (Tables VI-VIII).

Bone resorption. Significant increases in N.Oc and Oc/BS were detected in all three bones from the OVX control group, as compared with the sham control group $(\mathrm{P}<0.01)$. However, they appeared to be significantly decreased by Polycan treatment in a dose-dependent manner $(\mathrm{P}<0.05$; Tables VI-VIII).

Bone formation. Significant increases in the MAR, Md.Pm and BFR/BS were detected in the trabecular and cortical bone regions of all three bone types in the OVX control group compared with the sham control group $(\mathrm{P}<0.01)$. Conversely, the histomorphometrical indices for bone formation were significantly increased in the trabecular and cortical bone regions in the Polycan-treated groups compared with the OVX control group, in a dose-dependent manner. An exception was the $31.25 \mathrm{mg} / \mathrm{kg}$ Polycan-treated group, in which no significant increases in the histomorphometrical indices for bone formation were detected $(\mathrm{P}>0.05$; Tables VI-VIII).

\section{Discussion}

The present study investigated the protective effects of Polycan in a rat model of ovariectomy-induced osteoporosis by measuring alterations in the BMC, BMD, FL, serum levels of osteocalcin, bALP, Ca and $\mathrm{P}$, urine $\mathrm{Dpd} /$ creatinine ratios and histomorphometrical indices.

In a previous study, changes in the body weight (lean and/or fat mass) of OVX rodents was used to predict bone density (29); however, no significant ovariectomy-induced alterations in body weight were detected in the present study.

Osteocalcin is a protein secreted by mature osteoblasts, levels of which have previously been shown to correlate with active bone formation and resorption (30). In the present study, the serum levels of osteocalcin were significantly decreased in OVX mice following treatment with Polycan for 126 days; thus suggesting that Polycan may inhibit high bone turnover. bALP levels are generally accepted as a marker of bone formation (12). Decreased serum bALP levels by OVX were significantly and dose-dependently inhibited by Polycan treatment. Increased serum levels of $\mathrm{Ca}$ and $\mathrm{P}$ have previously been demonstrated to be a marker of bone formation in animal models of osteoporosis $(31,32)$. In the present study, increased serum levels of $\mathrm{Ca}$ and $\mathrm{P}$ were detected in the Polycan-treated groups compared with the OVX control group; thus suggesting that Polycan was able to inhibit the OVX-induced reduction in serum $\mathrm{Ca}$ and $\mathrm{P}$ levels. These results suggested that Polycan may improve bone formation in a dose-dependent manner.

Urine Dpd levels, which are considered to be a marker of bone resorption, alter in response to alterations in the levels of creatinine, which is an indicator of kidney state (33). Therefore, urine $\mathrm{Dpd} /$ creatinine ratios are considered a valuable marker of bone resorption in osteoporosis (12). In the present study, Polycan markedly attenuated ovariectomy-induced increases in the urine Dpd/creatinine ratios; thus suggesting that Polycan was able to decrease ovariectomy-induced bone resorption. Similar effects have been observed in OVX rats treated with alendronate (34).

Patients with osteoporosis typically exhibit a significantly decreased BMC (35). Among the various minerals that comprise bone, the levels of $\mathrm{Ca}$ and $\mathrm{P}$ have been shown to be the most significantly decreased in osteoporotic bones, although the $\mathrm{Ca} / \mathrm{P}$ ratio is not typically altered (36). In the present study, the concentrations of $\mathrm{Ca}$ and $\mathrm{P}$ in the tibia, femur and $\mathrm{L}_{4}$ bones of the Polycan-treated rats were significantly increased compared with the OVX control group, and this was associated with increases in bone strength and quantity, as determined by BMD.

BMD is considered to be a valuable clinical indicator of alterations in bone quality, and has been shown to be significantly decreased in animals with osteoporosis, regardless of the underlying cause. Furthermore, BMD has previously been used to predict the efficacy of anti-osteoporosis agents (37), and has provided diagnostic profiles of bone quality in human clinical research (38). In the present study, Polycan was able to inhibit ovariectomy-induced decreases in BMD; thus suggesting that Polycan may be used to prevent and/or treat osteoporosis-associated fractures.

FL is an key index for predicting the efficacy of anti-osteoporosis agents (39), since it has been directly correlated with cortical bone strength. In the present study, Polycan was able to improve the FL; thus suggesting that Polycan may directly inhibit ovariectomy-induced reductions in bone strength.

Bones may be observed under the microscope in order to analyze alterations in bone morphology (40). The histomorphometrical indices of bone mass and structure, and bone resorption, have been shown to be markedly decreased in patients with osteoporosis; thus they may be considered reliable markers for predicting the efficacy of anti-osteoporosis agents (41). In the present study, the histomorphometric indices for bone mass and structure, and bone resorption, were markedly reduced in the Polycan-treated rats. In a previous study, the histomorphometric indices for bone formation were increased in OVX animals due to an increase in bone turnover (42). In a previous study, dynamic histomorphometric indices have been shown to be a reliable indicator of whether a test compound is able to promote bone-formation (43). Therefore, the increase in the histomorphometric indices of bone formation in the Polycan-treated rats in the present study suggested that Polycan may exert bone anabolic effects. Increases in the histomorphometrical indices of bone formation have previously been demonstrated for other bone anabolic agents, including the parathyroid hormone analogs (44). However, they were not detected following treatment with selective estrogen receptor modulators (12) and bisphosphonate (45). Furthermore, alendronate has been shown to stabilize the indices for bone mass and structure and bone resorption; however, dynamic histomorphometry demonstrated that the indices for bone formation were markedly decreased following treatment with alendronate $(45,46)$. 
The results of the present study suggested that Polycan was able to effectively inhibit ovariectomy-induced changes associated with osteoporosis through the promotion of osteoblast differentiation and bone formation, and the inhibition of bone resorption and osteoclast activity, as has been previously demonstrated in mouse and in vitro studies $(20,21)$. The present study demonstrated that Polycan was able to preserve bone mass and strength, and to increase the rate of bone formation in the trabecular and cortical bone regions in OVX rats; thus suggesting that Polycan may be considered a potentially effective anti-osteoporosis agent. Further studies are required in order to determined how Polycan is able to stimulate the biomarkers of bone formation and absorption.

\section{Acknowledgements}

The present study was supported by the National Research Foundation of Korea, and funded by the Korea government (grant no. 2011-0030124) and the Korea Healthcare Technology R\&D Project, Ministry for Health, Welfare and Family Affairs, Korea (grant no. A091049-1012-0000400).

\section{References}

1. Sakai A, Nishida S, Okimoto N, Okazaki Y, Hirano T, Norimura T, Suda T and Nakamura T: Bone marrow cell development and trabecular bone dynamics after ovariectomy in ddy mice. Bone 23: 443-451, 1998.

2. Madureira MM, Ciconelli RM and Pereira RM: Quality of life measurements in patients with osteoporosis and fractures Clinics (Sao Paulo) 6: 1315-1320, 2012.

3. Melton LJ III, Chrischilles EA, Cooper C, Lane AW and Riggs BL: How many women have osteoporosis? JBMR Anniversary Classic. JMBR, Volume 7, Number 9, 1992. J Bone Miner Res 20: 886-892, 2005.

4. Rodan GA and Martin TJ: Therapeutic approaches to bone diseases. Science 289: 1508-1514, 2000.

5. Chen JS and Sambrook PN: Antiresorptive therapies for osteoporosis: A clinical overview. Nat Rev Endocrinol 8: 81-91, 2011.

6. Gowen M, Emery JG and Kumar S: Emerging therapies for osteoporosis. Expert Opin Emerg Drugs 5: 1-43, 2000.

7. Girotra M, Rubin MR and Bilezikian JP: Anabolic agents for osteoporosis: What is their likely place in therapy? Treat Endcrinol 5: 347-358, 2006.

8. Kalu DN: The ovariectomized rat model of postmenopausal bone loss. Bone Miner 15: 175-191, 1991.

9. Frost HM and Jee WS: On the rat model of human osteopenias and osteoporoses. Bone Miner 18: 227-236, 1992.

10. Wronski TJ, Yen CF and Scott KS: Estrogen and diphosphonate treatment provide long-term protection against osteopenia in ovariectomized rats. J Bone Miner Res 6: 387-394, 1991.

11. Kimmel DB, Recker RR, Gallagher JC, Vaswani AS and Aloia JF: A comparison of iliac bone histomorphometric data in post-menopausal osteoporotic and normal subjects. Bone Miner 11: 217-235, 1990.

12. Ke HZ, Foley GL, Simmons HA, Shen V and Thompson DD: Long-term treatment of lasofoxifene preserves bone mass and bone strength and dose not adversely affect the uterus in ovariectomized rats. Endocrinology 145: 1996-2005, 2004.

13. Manolagas SC, Kousteni S and Jilka RL: Sex steroids and bone. Recent Prog Horm Res 57: 385-409, 2002.

14. Bone HG, Hosking D, Devogelaer JP, Tucci JR, Emkey RD, Tonino RP, Rodriguez-Portales JA, Downs RW, Gupta J, Santora AC and Liberman UA; Alendronate Phase III Osteoporosis Treatment Study Group: Ten years' experience with alendronate for osteoporosis in postmenopausal women. N Engl J Med 350: 1189-1199, 2004.

15. Strewler GJ: Decimal point-osteoporosis therapy at the 10-year mark. N Engl J Med 350: 1172-1174, 2004.

16. Lauritzen DB, Balena R, Shea M, Seedor JG, Markatos A, Le HM, Toolan BC, Myers ER, Rodan GA and Hayes WC: Effects of combined prostaglandin and alendronate treatment on the histomorphometry and biomechanical properties of bone in ovariectomized rats. J Bone Miner Res 8: 871-879, 1993.
17. McClung MR, Wasnich RD, Hosking DJ, Christiansen C, Ravn P, Wu M, Mantz AM, Yates J, Ross PD and Santora AC II; Early Postmenopausal Intervention Cohort Study: Prevention of postmenopausal bone loss: Six-year results from the early postmenopausal intervention cohort study. J Clin Endocrinol Metab 89: 4879-4885, 2004.

18. Bell NH: Advances in the treatment of osteoporosis. Curr Drug Targets Immune Endocr Metabol Disord 1: 93-102, 2001.

19. Boivin G and Meunier PJ: The mineralization of bone tissue: A forgotten dimension in osteoporosis research. Osteoporos Int 14 (Suppl 3): S19-S24, 2003.

20. Shin HD, Yang KJ, Park BR, Son CW, Jang HJ and Ku SK: Antiosteoporotic effect of Polycan, beta-glucan from Aureobasidium, in ovariectomized osteoporotic mice. Nutrition 23: 853-860, 2007.

21. Song HB, Park DC, Do GM, Hwang SL, Lee WK, Kang HS, Park BR, Jang HJ, Son CW, Park EK, et al: Effect of exopolymers of Aureobasidium pullulans on improving osteoporosis induced in ovariectomized mice. J Microbiol Biotechnol 16: 37-45, 2006.

22. Park SO and Kim JM: Functional food for immune regulation - beta-glucan. Food Science and Industry 45: 39-47, 2012.

23. Estrada A, Yun CH, Van Kessel A, Li B, Hauta S and Laarveld B: Immunomodulatory activities of oat beta-glucan in vitro and in vivo. Microbiol Immunol 41: 991-998, 1997.

24. Bell S, Goldman VM, Bistrian BR, Arnold AH, Ostroff G and Forse RA: Effect of beta-glucan from oats and yeast on serum lipids. Crit Rev Food Sci Nutr 39: 189-202, 1999.

25. Seo HP, Kim JM, Shin HD, Kim TK, Chang HJ, Park BR and Lee JW: Production of $\beta-1,3 / 1,6$-glucan by Aureobasidium pullulans SM-2001. Korean J Bitechnol Bioeng 17: 376-380, 2002.

26. Lee HS, Cho HR, Moon SB, Shin HD, Yang KJ, Park BR, Jang HJ, Kim LS and Ku SK: Effect of $\beta$-glucan from Aureobasidium pullulans on rat rib fracture healing. Lab Anim Res 24: 39-44, 2008.

27. Han SY, Lee JR, Kwon YK, Jo MJ, Park SJ, Kim SC, Lee HS and $\mathrm{Ku}$ SK: Ostreae testa prevent ovariectomy-induced bone loss in mice by osteoblast activations. J Ethnopharmacol 114: 400-405, 2007.

28. Parfitt AM, Drezner MK, Glorieux FH, Kanis JA, Malluche H, Meunier PJ, Ott SM and Recker RR: Bone histomorphometry: Standardization of nomenclature, symbols, and units. Report of the ASBMR histomorphometry nomenclature committee. J Bone Miner Res 2: 595-610, 1987.

29. Lorden JF and Caudle A: Behavioral and endocrinological effects of single injections of monosodium glutamate in the mouse. Neurobehav Toxicol Teratol 8: 509-519, 1986.

30. Li B and Yu S: Genistein prevents bone resorption diseases by inhibiting bone resorption and stimulating bone formation. Biol Pharm Bull 26: 780-786, 2003.

31. Ladizesky MG, Cutrera RA, Boggio V, Somoza J, Centrella JM, Mautalen C and Cardinali DP: Effect of melatonin on bone metabolism in ovariectomized rats. Life Sci 70: 557-565, 2001.

32. Shim JG, Yeom SH, Kim HJ, Choi YW, Lee DI, Song KY, Kwon SH and Lee MW: Bone loss preventing effect of Sophorae Fructus on ovariectomized rats. Arch Pharm Res 28: 106-110, 2005.

33. Xu M, Dick IM, Day R, Randall D and Prince RL: Effects of a herbal extract on the bone density, strength and markers of bone turnover of mature ovariectomized rats. Am J Chin Med 31: 87-101, 2003.

34. Iwamoto J, Seki A, Takeda T, Sato Y, Yamada H and Yeh JK: Comparative therapeutic effects of alendronate and alfacalcidol on cancellous and cortical bone mass and mechanical properties in ovariectomized osteopenic rats. J Nutr Sci Vitaminol (Tokyo) 52: 1-8, 2006.

35. Pavlik M: Measuring bone mineral content. Orthop Nurs 10: 39-43. 1991.

36. Tanaka S, Shimizu M, Debari K, Furuya R, Kawawa T and Sasaki T: Acute effects of ovariectomy on wound healing of alveolar bone after maxillary molar extraction in aged rats. Anat Rec 262: 203-212, 2001.

37. Syed Z and Khan A: Bone densitometry: Applications and limitations. J Obstet Gynaecol Can 24: 476-484, 2002.

38. Diez F: Guidelines for the diagnosis of osteoporosis by densitometric methods. J Manipulative Physiol Ther 25: 403-415, 2002 . 
39. Bilston LE, Little DG, Smith NC, Williams P and Briody J Zoledronic acid improves the mechanical properties of normal and healing bone. Clin Biomech (Bristol, Avon) 17: 716-718, 2002.

40. Heikkinen T, Puoliväli J and Tanila H: Effects of long-term ovariectomy and estrogen treatment on maze learning in aged mice. Exp Gerontol 39: 1277-1283, 2004.

41. Weinreb M, Patael H, Preisler O and Ben-Shemen S: Short-term healing kinetics of cortical and cancellous bone osteopenia induced by unloading during the reloading period in young rats. Virchows Arch 431: 449-452, 1997.

42. Verhaeghe J, Oloumi G, van Herck E, van Bree R, Dequeker J, Einhorn TA and Bouillon R: Effects of long-term diabetes and/or high-dose 17 beta-estradiol on bone formation, bone mineral density, and strength in ovariectomized rats. Bone 20: 421-428, 1997.
43. Gal-Moscovici A, Gal M and Popovtzer MM: Treatment of osteoporotic ovariectomized rats with $24,25(\mathrm{OH}) 2 \mathrm{D} 3$. Eur J Clin Invest 35: 375-379, 2005.

44. Andersson N, Lindberg MK, Ohlsson C, Andersson K and Ryberg B: Repeated in vivo determinations of bone mineral density during parathyroid hormone treatment in ovariectomized mice. J Endocrinol 170: 529-537, 2001.

45. da Paz LH, de Falco V, Teng NC, dos Reis LM, Pereira RM and Jorgetti V: Effect of 17beta-estradiol or alendronate on the bone densitometry, bone histomorphometry and bone metabolism of ovariectomized rats. Braz J Med Biol Res 34: 1015-1022, 2001.

46. Broulik PD, Rosenkrancová J, Růzicka P and Sedlácek R: Effect of alendronate administration on bone mineral density and bone strength in castrated rats. Horm Metab Res 37: 414-418, 2005. 